\title{
A Techno-Economic Analysis of BEV Service Providers Offering Battery Swapping Services
}

\author{
Jeremy S. Neubauer and Ahmad Pesaran \\ National Renewable Energy Laboratory
}

doi: $\underline{10.4271 / 2013-01-0500}$

\begin{abstract}
Battery electric vehicles (BEVs) offer the potential to reduce both oil imports and greenhouse gas emissions, but high upfront costs, battery-limited vehicle range, and concern over high battery replacement costs may discourage potential buyers. A subscription model in which a service provider owns the battery and supplies access to battery swapping infrastructure could reduce upfront and battery replacement costs with a predictable monthly fee, while expanding BEV range. Assessing the costs and benefits of such a proposal are complicated by many factors, including customer drive patterns, the amount of required infrastructure, battery life, etc. The National Renewable Energy Laboratory has applied its Battery Ownership Model to compare the economics and utility of BEV battery swapping service plan options to more traditional direct ownership options. Our evaluation process followed four steps: (1) identifying drive patterns best suited to battery swapping service plans, (2) modeling service usage statistics for the selected drive patterns, (3) calculating the cost-of-service plan options, and (4) evaluating the economics of individual drivers under realistically priced service plans. A service plan option can be more costeffective than direct ownership for drivers who wish to operate a $\mathrm{BEV}$ as their primary vehicle where alternative options for travel beyond the single-charge range are expensive, and a full-coverage-yet-cost-effective regional infrastructure network can be deployed. However, under our assumed cost of gasoline, tax structure, and absence of purchase incentives, our calculations show the service plan $\mathrm{BEV}$ is rarely more cost-effective than direct ownership of a conventional vehicle.
\end{abstract}

\section{INTRODUCTION}

Plug-in electric vehicles, which include both plug-in hybrid electric vehicles and battery electric vehicles (BEVs), offer the potential to reduce both oil imports and greenhouse gases.
BEVs are particularly attractive for their potential to fully eliminate tailpipe emissions and the direct use of gasoline.

However, BEV batteries' high upfront and replacement costs, and battery-limited vehicle range discourage many potential purchasers.

A subscription model offering access to range extension infrastructure could reduce upfront and replacement costs for BEV batteries with a predictable monthly fee, while expanding range. In such a scenario, drivers would purchase a BEV without a battery-the most expensive element of a BEV-while a service provider would supply batteries in exchange for a monthly subscription fee. Subscribers would also gain access to a network of range extending infrastructure-such as public chargers or battery swapping stations, the latter functioning much like today's gas stations from the driver's point of view. For example, when a driver's battery was running low on energy mid-trip, the subscriber would pull into a battery swapping facility to quickly replace the nearly-empty in-vehicle battery with a fully-charged one. This would allow the vehicle to continue on to its final destination, with the range of BEV service limited by the scale and convenience of the battery swapping infrastructure, rather than by the size of the vehicle battery.

While there are many questions regarding consumer acceptance of such electrification strategies, economic issues are frequently raised. Economic comparison of this service plan option to traditional direct-ownership (DO), though, is not straightforward. Computing the total cost of ownership (TCO) of BEVs with a direct ownership (DO) scenario is challenging [1]. Adding a service provider and range extension technology to the equation makes this task even more complex. The principle additional difficulty is quantifying the economics of a service provider in order to estimate the fee that must be charged to each subscriber. This is complicated by the amount and cost of batteries and 
infrastructure that must be procured, which are, in turn, functions of how subscribers will utilize the services-which is, itself, dependent on subscriber driving patterns and vehicle capabilities. Battery lifespan is also crucial to consider, but difficult to quantify. Batteries operated within a swapping scenario would be subject to diverse and complex operational duty cycles specific to the interaction of vehicle platforms, driving habits, and availability of swapping infrastructure.

With support from the Vehicle Technologies Program in the U.S. Department of Energy, the National Renewable Energy Laboratory (NREL) has developed a vehicle TCO calculator known as the Battery Ownership Model (BOM) to evaluate and analyze these and other challenges associated with electric vehicles' lifecycle economics and advanced business strategies. We applied the BOM to compare the economics and utility of BEV battery swapping service plan (SP) options to more traditional DO options. We evaluated BEV battery swapping SPs via the following four steps: (1) identification of drive patterns best suited to a range extension SP, (2) modeling service usage statistics for the selected drive patterns, (3) calculation of the cost of SP options, and (4) evaluation of the economics of individuals driving realistically priced SPs.

\section{TOTAL COST OF OWNERSHIP CALCULATION APPROACH}

In this study we use the BOM to calculate the present value of the TCO for various vehicles and business strategies, applying hundreds of real world drive patterns. The BOM is an advanced TCO calculator that takes into account various vehicle and component cost scenarios, battery and fuel price forecasts, drive patterns, annual vehicle miles traveled (VMT), battery wear, purchase incentives, financing, ownership, and other criteria. Of particular relevance to this study is its ability to account for costs associated with thirdparty installation and operation of infrastructure, as well as the impact of complex battery duty cycles on battery wear $[\underline{1}-\underline{2}]$.

Our methods and assumptions are generally consistent with those in our past studies [1-2] , including use of 398 realworld longitudinal drive patterns from the Puget Sound Regional Council's Travel Choice Study (TCS) [3] , except when explicitly noted otherwise. The vehicles employed for this study, summarized in Table 1, are the same as those in the Journal of Power Sources [1], where a variable drivetrain is adapted to a standard platform similar to that of a Chevy Cruze to yield a 9 second $0-60 \mathrm{mph}$ acceleration time and, in the case of the BEVs, a specified range. The glider is assumed to cost $\$ 14,715.50$ per [1], while power electronics are priced at the DOE's 2015 target of $\$ 12 / \mathrm{kW}$ per [4] and multiplied by a 1.5 manufacturing to retail markup $[\underline{5}, \underline{6}, \underline{7}]$. Note that the vehicle retail price listed in Table 1 is the combination of the glider price plus the marked-up power electronics cost, and does not include the price of the battery (assumed to be covered by the service provider's monthly fee). Batteries are sized to provide the designated range while operating between a minimum SOC of $0 \%$ and the maximum SOC listed in Table 1. Both fuel and electricity consumption are calculated via simulation of the highway and urban driving dynamometer schedule, weighted and combined to be representative of the U.S. Environmental Protection Agency window sticker rating []ㅡ assuming a constant $300 \mathrm{~W}$ auxiliary load []].

\section{DIRECT OWNERSHIP ANALYSIS}

Prior to addressing the range extension service provider cases, we analyze two traditional competing alternatives consumers are likely to consider: (1) the DO of a CV, and (2) the DO of a BEV. The TCO for each vehicle is computed over all 398 TCS drive patterns assuming a 2015 vehicle purchase year, 15-year analysis period, and 8\% driver discount rate. Average taxes and insurance rates are included, as are tire and maintenance costs set at $\$ 0.0533$ per mile for both CVs and BEVs, per the AAA's 2010 estimate of typical mid-size car costs [10]. While there is motivation to believe that the maintenance cost of BEVs is less than that of CVs, we exclude that factor due to the lack of necessary data to quantify the difference.

For the CV we employ the vehicle specifications of Table 1 to yield a $32 \mathrm{mpg}$ vehicle with an upfront price of $\$ 17,687$ (in 2012 dollars) [1]. National average gasoline price forecasts, as reported in the Energy Information Administration's (EIA's) 2011 high oil price scenario [10], are employed to calculate recurring energy costs (Figure 1). This scenario is selected as it best agrees with EIA's reported actual 2011 gasoline costs [11]. Accrued VMT follows the TCS drive patterns directly, as there are no daily range restrictions placed upon this vehicle. No independent infrastructure costs are associated with this scenario.

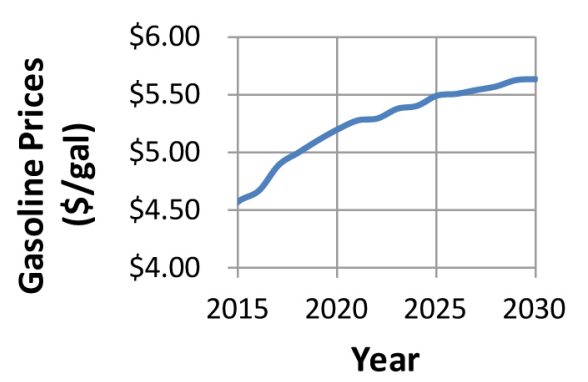

Figure 1. Employed gasoline prices (2012 dollars)

For the BEV we employ the Table 1 vehicle specifications for the 75-mile-range BEV utilizing a $100 \%$ maximum SOC, as this was identified as the most cost-effective BEV solutions when the cost of unachievable VMT is high (e.g., single vehicle households) [1] and is a reasonable representation of currently available BEV options. Three different battery costs 
Table 1. Vehicle Specifications (all prices in 2012 U.S. dollars)

\begin{tabular}{|c|c|c|c|c|c|c|}
\hline Vehicle & $\begin{array}{l}\text { Electric Range } \\
\text { (mi) }\end{array}$ & $\begin{array}{l}\text { Maximum } \\
\text { SOC }\end{array}$ & $\begin{array}{l}\text { Engine or Motor } \\
\text { Power }(\mathrm{kW})\end{array}$ & $\begin{array}{c}\text { Battery Energy } \\
(\mathrm{kWh})\end{array}$ & $\begin{array}{l}\text { Vehicle Efficiency } \\
\qquad(\mathrm{kWh} / \mathrm{mi})\end{array}$ & $\begin{array}{l}2015 \text { Vehicle } \\
\text { Retail Price (w/o } \\
\text { Battery) }\end{array}$ \\
\hline $\mathrm{CV}$ & 0 & $\mathrm{n} / \mathrm{a}$ & 100 & 0 & $32 \mathrm{mi} / \mathrm{gal}$ & $\$ 17,687$ \\
\hline \multirow{3}{*}{ BEV50 } & \multirow{3}{*}{50} & $100 \%$ & 79.7 & 16.6 & 0.332 & $\$ 16,150$ \\
\hline & & $95 \%$ & 80.3 & 17.5 & 0.333 & $\$ 16,161$ \\
\hline & & $90 \%$ & 80.8 & 18.6 & 0.334 & $\$ 16,170$ \\
\hline \multirow{3}{*}{ BEV75 } & \multirow{3}{*}{75} & $100 \%$ & 85.3 & 25.7 & 0.343 & $\$ 16,252$ \\
\hline & & $95 \%$ & 86.3 & 27.2 & 0.345 & $\$ 16,268$ \\
\hline & & $90 \%$ & 87.2 & 28.8 & 0.347 & $\$ 16,285$ \\
\hline \multirow{3}{*}{ BEV100 } & \multirow{3}{*}{100} & $100 \%$ & 91.1 & 35.4 & 0.355 & $\$ 16,356$ \\
\hline & & $95 \%$ & 93.0 & 37.6 & 0.358 & $\$ 16,390$ \\
\hline & & $90 \%$ & 94.4 & 40.0 & 0.361 & $\$ 16,415$ \\
\hline
\end{tabular}

$(\$ 125 / \mathrm{kWh}, \$ 300 / \mathrm{kWh}$, and $\$ 475 / \mathrm{kWh})$ that span the DOE's advanced battery cost targets [12] and several industry battery cost forecasts $[13,28,29]$ are applied and assumed constant through our period of analysis. Note that these values are assumed to be applicable to usable battery energy, enabling our use of a $0 \%$ minimum SOC. For our low, medium, and high battery costs, the 2015 purchase price for this BEV comes to $\$ 26,653 ; \$ 33,400$; and $\$ 40,146$, respectively, after adding the battery to the values of Table 1 and applying a manufacturer-to-retail markup factor of $1.5[\underline{5}, \underline{6}, \underline{7}]$. We assume no tax credits or other purchase incentives are available.

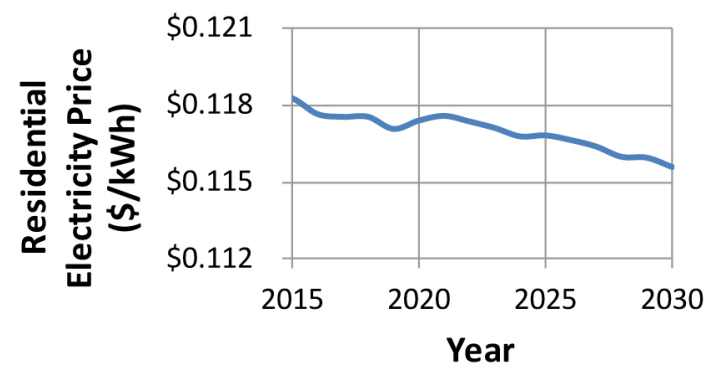

Figure 2. Employed residential electricity prices (2012 dollars)

Residential customer electricity price projections from the EIA's 2011 baseline scenario [1] ] reproduced in Figure 2 are used to calculate energy costs, as its 2011 values agree well with actual prices [11]. The amount of energy consumed is calculated based upon an $85 \%$ charging efficiency and the achieved annual VMT, which changes annually in response to battery degradation.

Battery degradation is calculated using a high-fidelity degradation model [14] that projects capacity loss and resistance growth at the end of each service year based on the selected drive pattern, a just-in-time charge strategy, and national average environmental conditions. Minimum SOC is adjusted each year such that no less than $80 \%$ of beginningof-life (BOL) power can be delivered at the end of charge depleting operation without violating battery minimum voltage requirements, translating the effect of power fade to a reduction in available energy and vehicle range. In addition to calculating achieved VMT, we also leverage this capability to employ bounded, cost-optimal battery replacement schedules[1].

A cost is applied to unachievable VMT per the high-cost approach [1], which assumes that a CV is rented via a carshare program on days where the daily vehicle miles traveled exceeds the range capability of the car. This is selected over the low-cost approach (representative of a multi-car household with an additional $\mathrm{CV}$ available for long trips) to better represent likely candidates for a battery swapping SP or other range extension options - those without an additional means of convenient, long-range transportation available.

The only infrastructure cost associated with this scenario is a $32 \mathrm{amp}, 240 \mathrm{~V}$ charger priced at $\$ 1,200$ installed at the owner's most convenient location. 


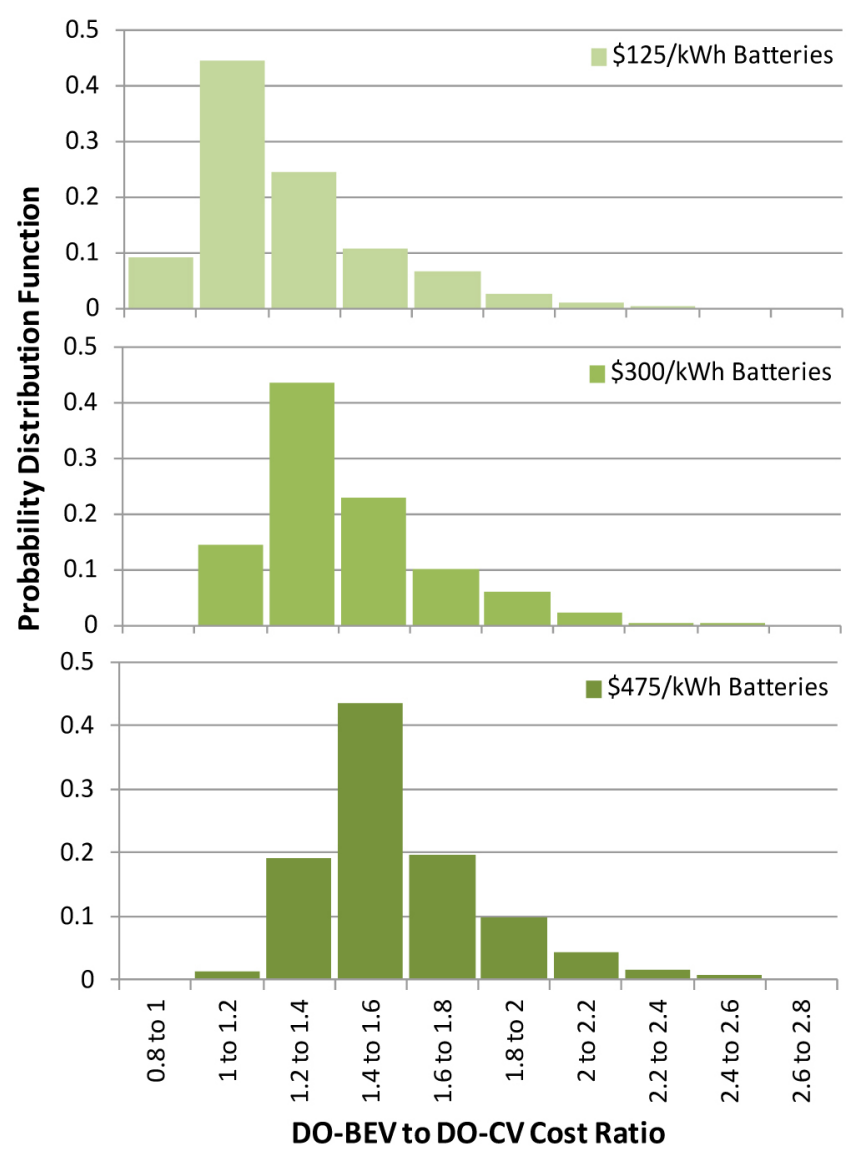

Figure 3. DO-BEV to DO-CV cost ratio distributions

We compare the TCO of the DO-BEV to that of the DO-CV with the aforementioned conditions for all 398 drive patterns in Figure 3. We see that for the low cost of batteries scenario, $9 \%$ of the simulated drive patterns receive a cost benefit to electing a DO-BEV over a DO-CV. Forty-five percent of the simulated drive patterns achieve a DO-BEV TCO greater than, but within $20 \%$ of that of a DO-CV, while the remaining $46 \%$ of simulated drive patterns incur a TCO premium of $20 \%$ or greater when electing to drive a DO-BEV rather than a DO-CV. With the medium and high battery prices, however, no simulated drive patterns see a cost advantage to driving a DO-BEV, and much larger percentages of simulated drive patterns incur a TCO premium of $20 \%$ or more when electing the DO-BEV.

A significant factor in calculating these economic trends is the assumption of the high cost of unachievable VMT. In contrast to these results, similar comparisons with the low cost of unachievable VMT assumption show that a larger fraction of drive patterns can benefit financially from a DOBEV [1]. However, the low cost of unachievable VMT assumption is generally not as applicable to single-vehicle households as the alternative high-cost assumption is, and certainly some of these households will have a desire to purchase a BEV. This provides the motive for our investigation of a BEV operated with a SP providing battery swapping for these households, reducing the amount and cost of unachievable VMT.

\section{BATTERY SWAPPING SERVICE PROVIDER ANALYSIS}

In this section we assess the TCO to the consumer of BEVs operated with battery swapping SPs. SP fees are calculated using a bottom-up approach that accounts for all of the service provider's battery, infrastructure, electricity, and other costs, as well as the cost of financing such an operation. There are four phases to this analysis:

(1). Analyzing all 398 drive patterns to down-select a subset of drive patterns suitable for more detailed battery swapping analysis

(2). Identifying average service usage statistics for this subset of drive patterns, including battery life, electricity usage, and battery swapping frequency

(3). Calculating SP fees for multiple scenarios based on the identified service usage statistics and a rigorous economic model of the service provider's business

(4). Investigating individual driver economics with the calculated SP fees

\subsection{Identifying Drive Patterns Suitable to Service Plan BEVs with Range Extension}

To identify drive patterns most suitable to a SP-BEV with range extension for further study, we assess the economics of SP-BEVs when the range extension features are perfect and without limit. We select the drive patterns that show the most potential for economic savings over either a DO-CV or a DO$\mathrm{BEV}$ on the basis that both are important criteria for a consumer to consider when electing to subscribe to such an SP. TCO is computed as it is for the DO-BEV, but (1) all battery, infrastructure, and electricity costs are replaced by a flat-rate monthly service fee, and (2) we assume all VMT in the drive pattern is achievable via implementation of a perfect range extension technology.

We calculate the SP TCO for a monthly fee ranging from $\$ 100$ to $\$ 600$ per month to the TCO of each direct ownership scenario for all of the 398 TCS drive patterns. Note that these are assumed monthly SP fees, not calculated. Although this range of SP fees are shown later to largely encompass our bottom-up calculated SP fees, they are selected at this point in the analysis only to support the identification of relevant drive patterns. We compare the resultant SP-BEV TCO to that of the DO-CV and three DO-BEV cases, each with different battery cost coefficients $(\$ 125 / \mathrm{kWh}, \$ 300 / \mathrm{kWh}$, and $\$ 475 / \mathrm{kWh}$ ).

We find that the SP economics viewed by the driver are generally indifferent to vehicle range, swapping 


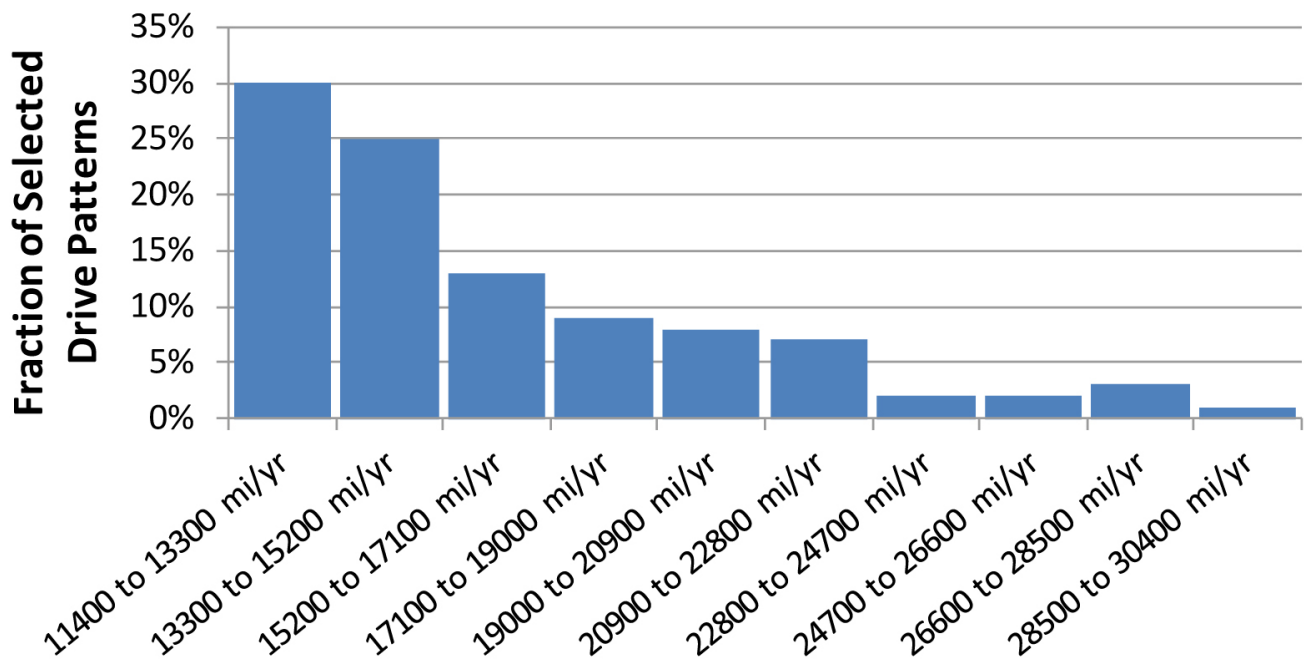

Figure 4. Annual VMT distribution of selected drive patterns

infrastructure, electricity cost, battery degradation, etc., due to the assumption of perfect range extension technology and the flat monthly SP fee. However, the specific drive patterns best suited to the SP option vary slightly as a function of both the monthly service provider fee and the basis of comparison (CV, BEV with $\$ 125 / \mathrm{kWh}$ batteries, BEV with $\$ 300 / \mathrm{kWh}$ batteries, or BEV with $\$ 475 / \mathrm{kWh}$ batteries). This poses a minor challenge to down-selecting the most relevant drive patterns for further study, since the actual service provider fee is not yet known, battery cost is a variable we would like to continue to include, and comparisons to both DO-CV and DO-BEV options are relevant to a consumer's decision to elect a SP-BEV. The cost of a SP-BEV must be competitive against both a DO-CV and a DO-BEV to be viable on a mass market scale.

To solve this problem, we implement a scoring system to grade each drive pattern based upon its calculated cost-ratio relative to that of all other drive patterns with each service provider fee and basis for comparison. We then average the grade of each drive pattern across all service provider fees and, in the case of the BEV basis, all battery costs, as well. This creates two sets of drive pattern rankings-one sorting drive patterns on their suitability for a SP-BEV in comparison to a DO-CV, the other on their suitability for a SP-BEV in comparison to a DO-BEV. From each set we isolate the top 125 drive patterns, then take the intersection of each reduced set to yield a 100 drive pattern subset for continued study.

Perhaps unsurprisingly, the defining characteristic of drive patterns in this subset is simply annual mileage. The minimum annual VMT of the selected subset is 11,471 miles, and every drive pattern with an annual VMT greater than 16,446 miles from the full TCS data set has been included ( $10 \%$ of the entire TCS data set, but $40 \%$ of the 100 selected drive patterns). This is logical given that our 100 selected drive patterns are parsed on an economic basis where the primary means of financial benefit is reducing the cost of gas expenditures (which rises with increased VMT), and the limitations of achievable mileage have been eliminated by the assumption of a perfect range extension technology. The distribution of annual VMTs of this selection is shown in Figure 4.

As designed, the results of this section are applicable to the theoretical limits of any range extension technology, inclusive of not only battery swapping, but also opportunity charging, fast charging, electric roadways, etc.

\subsection{Service Usage Statistics}

Now we analyze the service usage patterns of the selected 100 drive patterns with the application of more realistic assumptions around the VMT achievable via battery swapping. Relative to both the perfect range extension and direct ownership cases, our improved set of assumptions for BEVs operated with a battery swapping SP affects three factors that must be accounted for to model service usage statistics: achievable VMT, battery degradation, and battery replacement criteria.

Achievable VMT is affected primarily by vehicle range and range extension infrastructure. We consider three vehicle ranges $(50,75$, and 100 miles) and three maximum SOCs $(90 \%, 95 \%$, and $100 \%)$ with the vehicle properties as defined in Table 1. The combination of vehicle range with time constraints to complete a day's driving, range extensions, and home charging, as well as with the perceived inconvenience of range extension stops, will limit daily VMT. We account for the impact of time limitations by allocating a maximum of 24 hours to a day's driving, range extension, and home charging activities (allowing successive back-to-back occurrences of the most demanding drive days). We assume a range extension event occurs only when the battery is completely empty and that a battery swap spot is immediately available at this point in time and space. In doing so, we do 
not factor in the effects of imperfect battery state of health identification and vehicle range prediction, driver psychology around range anxiety, and temporal and spatial availability of battery swapping infrastructure. While these are important factors, we must exclude them from this study due to the lack of necessary supporting data and analysis resources. However, we do restrict the number of range extensions to a maximum of four per day as a proxy for these effects and the willingness of drivers to change behavior. Where more than four range extensions would be required by a day's driving, or when the time required to complete the driving, charging, and range extensions exceeds 24 hours, we assume that the driver instead acquires a vehicle from a car-share program. Note that car-share cost accounting is performed as detailed in the Journal of Power Sources [1] and is not a cost covered by the SP per our assumptions, although in practice this could be something a SP may offer with its BEV services.

Battery degradation is affected by the different cycle and SOC history induced by the utilization of range extension infrastructure, thus we must modify our input to the battery degradation algorithm to accurately represent the battery swapping SPs. Most apparently, we must account for the increased cycling induced by range extension. These extra cycles include a relatively fast 30 -minute charge to minimize the service provider's investment in costly batteries at swap stations. Unfortunately, the battery degradation model we employ does not account for additional wear mechanisms induced by high-rate charging. Although an argument might be made that the incremental wear of such high-rate charging is minimal on the grounds that the time at peak charge rate of approximately $2.5 \mathrm{C}$ is limited to much less than 30 minutes due to voltage related limitations [15], we instead apply an artificial fast-charge wear factor to these cycles to increase their effect on capacity and resistance degradation by a userdefined value. For this study we shall employ fast-charge wear factors of 1 and 10 to mimic the possible effect of fast charging on battery wear and to investigate the economic sensitivity thereof. The fast-charge wear factor of 1 implies that there is no added effect of the increased charge rates - all fast charges are accounted for within the battery wear model as normal cycles. The fast-charge wear factor of 10 , on the other hand, logs 10 normal cycles in place of every single fast-charge cycle, thus, the effect on capacity loss and resistance gain of fast-charge cycles is increased by a factor of 10 relative to a slow-charge alternative.

We must also account for the slight surplus of batteries greater than that of vehicles due to the presence of additional batteries charging at swap stations, which effectively decreases the amount of cycling for each battery. Assuming for now that 7 batteries are being charged or are resting at a swap spot for every 100 vehicles on the road, we simulate 7 days of rest for every 100 days dictated by the drive pattern. Though the ratio of extra batteries to vehicles is selected arbitrarily at this point in the analysis, subsequent results shall prove them to be relevant estimates. Finally, in both cases, home charging is largely unaffected; we continue to assume that home charging is performed on a just-in-time schedule, such that the maximum SOC is reached just prior to the vehicle's first departure of the day.

It is further necessary to adjust the battery replacement criteria. In the direct-ownership case, we applied a costoptimal replacement schedule. As discovered in the Journal of Power Sources [1], such an approach to battery replacement typically results in long battery lifetimes and significantly reduced vehicle range near end of life (EOL). Although this may be financially optimal for individual drivers, it is unlikely that a SP subscriber would tolerate the high degree of uncertainty and variability of range following a battery swap that may result. Accordingly, we enforce a battery EOL condition of $80 \%$ BOL range at $80 \%$ BOL power to increase the predictability of vehicle range and performance following a battery swap event, thus improving consumer satisfaction.

The resultant average battery life, number of annual battery swaps, and annual electricity consumption are reported in Table 2 for every combination of vehicle range, maximum SOC, and fast-charge wear factor. As might be expected, we find that the number of annual battery swaps is reduced by increased vehicle range; average battery life is extended when vehicle range is increased from 50 to 75 miles due to decreased cycling. It is worth noting that increasing the vehicle range from 75 to 100 miles decreases battery life slightly, presumably due to higher average SOCs through life.

In addition, a strong sensitivity of battery life to the maximum SOC is clearly observed. Fast-charge wear factor is shown to reduce battery lifetime noticeably for all BEV50 scenarios, presumably due to the much increased range extension frequency, but is seen to have little to no effect on the BEV75 and BEV100 cases.

Table 2 also shows the utility factor for each scenario, defined as the ratio of miles traveled electrically in a BEV to the total VMT defined by the original drive pattern. Recall that we impose a maximum of four battery swaps per day, which reduces the frequency at which the SP-BEV is utilized. The time required for driving, charging, and battery swapping also affects SP-BEV utilization. For the cases studied, we find that vehicle range is the primary determinant of the utility factor, yielding $85 \%, 89 \%$, and $94 \%$ utility factors for the 50-, 75-, and 100-mile SP-BEVs, respectively. Clearly all cases are capable of completing a large fraction of driver miles electrically. The fact that these values are not closer to $100 \%$, though, implies that an alternative mode of transportation will still need to be procured occasionally for many drivers. 
Table 2. Calculated Battery Swapping Service Plan Usage Statistics

\begin{tabular}{|c|c|c|c|c|c|c|}
\hline Range & Max SOC & $\begin{array}{l}\text { Fast-charge } \\
\text { Wear Factor }\end{array}$ & $\begin{array}{l}\text { Battery Life } \\
(\text { yrs })\end{array}$ & $\begin{array}{c}\text { Annual Electricity } \\
(\mathbf{k W h})\end{array}$ & $\begin{array}{c}\text { Swaps per Year } \\
\text { (No.) }\end{array}$ & Utility Factor \\
\hline \multirow{6}{*}{$50 \mathrm{mi}$} & \multirow{2}{*}{$100 \%$} & 1 & 8.4 & 5684 & 158.4 & $86 \%$ \\
\hline & & 10 & 6.6 & 5673 & 157.9 & $85 \%$ \\
\hline & \multirow{2}{*}{$95 \%$} & 1 & 11.1 & 5681 & 152.7 & $85 \%$ \\
\hline & & 10 & 8.6 & 5675 & 150.8 & $85 \%$ \\
\hline & \multirow{2}{*}{$90 \%$} & 1 & 14.2 & 5670 & 150.1 & $85 \%$ \\
\hline & & 10 & 11.6 & 5672 & 147.3 & $85 \%$ \\
\hline \multirow{6}{*}{$75 \mathrm{mi}$} & \multirow{2}{*}{$100 \%$} & 1 & 9.0 & 6059 & 71.8 & $89 \%$ \\
\hline & & 10 & 8.9 & 6055 & 71.8 & $89 \%$ \\
\hline & \multirow{2}{*}{$95 \%$} & 1 & 12.3 & 6059 & 70.5 & $89 \%$ \\
\hline & & 10 & 12.1 & 6066 & 70.4 & $89 \%$ \\
\hline & \multirow{2}{*}{$90 \%$} & 1 & 14.7 & 6066 & 66.3 & $89 \%$ \\
\hline & & 10 & 14.6 & 6072 & 66.5 & $89 \%$ \\
\hline \multirow{6}{*}{$100 \mathrm{mi}$} & \multirow{2}{*}{$100 \%$} & 1 & 8.4 & 6572 & 43.2 & $94 \%$ \\
\hline & & 10 & 8.4 & 6572 & 43.2 & $94 \%$ \\
\hline & \multirow{2}{*}{$95 \%$} & 1 & 11.5 & 6596 & 41.9 & $94 \%$ \\
\hline & & 10 & 11.5 & 6597 & 41.9 & $94 \%$ \\
\hline & \multirow{2}{*}{$90 \%$} & 1 & 14.4 & 6600 & 39.8 & $94 \%$ \\
\hline & & 10 & 14.4 & 6600 & 39.8 & $94 \%$ \\
\hline
\end{tabular}

\subsection{Service Provider Fee}

Now we apply the usage statistics for likely subscribers acquired in Section 4.2 to calculate actual monthly service provider fees with various scenarios. To do so, we construct a financial model of a service provider that includes all capital and recurring costs, return on equity (ROE), cost of debt, etc., and then calculate the monthly fee charged to customers that enables the business to meet its ROE requirements after 15 years of operation.

\subsubsection{Financial Accounting}

The business of our service provider is very capital intensive due to the cost of batteries, range extension infrastructure, and charging infrastructure. Thus, the means of financing the business is expected to have a considerable impact on the required service provider fee. In this analysis, we assume that the service provider acquires the necessary capital to finance the battery and infrastructure purchases of the first year of operation equally from debt and equity investments at the beginning of that year. The cost of these expenditures is determined as discussed below, assuming an initial customer base of 10,000 subscribers. The cost of debt is varied from $4 \%$ to $12 \%$, with annual debt payments calculated to pay off the full balance in 15 years where interest accrues annually. Our assumed ROE is coupled to the cost of debt, ranging from $5 \%$ to $15 \%$.

Annual revenue is calculated from the monthly service provider fee and the number of customers. From this the gross taxable income is computed after deducting annual operating expenses (described below), interest payments on debt, depreciation of assets, and any applicable loss carry- forwards from previous years. Asset depreciation includes batteries (annualized per the calculated average battery life of Table 2), battery swapping infrastructure (annualized at 5\%/ $\mathrm{yr}$ ), and charging infrastructure (annualized at 5\%/yr). Taxes are then computed against the gross taxable income assuming an average $39.3 \%$ corporate tax rate [17].

The remaining working capital at the end of each year is calculated by subtracting the annual debt payment, operating expenses, and taxes from the annual revenue. We assume this remaining capital is spent in the subsequent year to buy batteries and build infrastructure to support additional customers. As such, the profit from year one determines the increase of customers in year two, and so on.

The monthly service fee charged is determined by an iterative process to ensure that the company net worth at year 15 is equal to the value of the initial equity investment after 15 years of growth at the prescribed ROE. For example, if the required battery and infrastructure expenses for year one totals \$2 million and a 15\% ROE is specified, our requirement would demand that the monthly service fee is set to result in a business with a net worth of $\$ 8.14$ million at the end of year 15-equivalent to the value of the initial equity investment ( $\$ 1$ million) growing at 15\% per year for 15 years (the remaining $\$ 1$ million of initial costs are covered by loans). The net worth of the company at year 15 is defined simply as the sum of all past capital expenditures, minus the sum of all past depreciation taken, plus the profit made in the final year (note that the debt term aligns with the analysis term, and the company has no debt remaining at year 15 to consider). 


\subsubsection{Charging and Range Extension Infrastructure}

The total cost of home charging infrastructure is computed from the number of new subscribers each year and a flat fee of $\$ 1,200$ per charge point installed.

To compute the cost of deployed range extension infrastructure, we must first calculate the amount of deployed infrastructure. While we recognize that the amount of deployed infrastructure will be dependent on traffic patterns, geography, and acceptable customer wait-times for battery swaps in practice, addressing this level of detail is beyond the scope of this study. Instead, we develop a proxy approach that attempts to calculate the amount of range extension infrastructure that would offer a level of battery swap-spot convenience and availability equivalent to today's network of gasoline pumps.

We begin this proxy approach by defining the battery swapspot utilization rate as the average hours per day that the battery swap spot is occupied by a customer. To provide similar service quality to the BEV driver as gas stations provide today's CV drivers, we set our baseline swap spot utilization rate equivalent to that of the average gas pump. Our calculations indicate that the average gas pump is occupied approximately $1.2 \mathrm{hrs}$ per day, based upon the amount of fuel consumed between light-, medium-, and heavy-duty vehicles [18]. We assume an average fuel tank size of 18 gallons for light-duty and 200 gallons for mediumand heavy-duty vehicles, and a maximum pump flow rate of 10 gallons per minute [19]. We calculate an average of 3 extra minutes per stop for payment processing and other activities, and from the number of fueling stations [20] and average pumps per station [ㄷ] $]$ in the United States. We also employ a three times larger utilization rate of 3.7 hours per day for swap spots as an upper bound, allowing a battery swap spot to be occupied three times as much as an average gas pump. Increasing the swap-spot utilization rate in this way decreases the total required cost of infrastructure a service provider deploys on a per-customer basis, but may also decrease the level of service to the customer, and thereby customer satisfaction.

From here we can compute the ratio of customers per battery swap spot by dividing the utilization rate by the average time per day each customer spends at a battery swap spot. The average battery swap-spot time per day per customer is calculated by multiplying the average number of annual range extensions per subscriber (Table 2) by the time required per swap $\{1$ minute for a battery swap [27], and 2 minutes for margin and related activities; note that waiting time is not included \}and dividing by 365 days per year. For the battery swapping scenarios we find this ratio to vary from a low of 61 customers per swap spot for the BEV50 with a 1.2 hour per day utilization rate, to a high of 680 vehicles per swap spot for the BEV100 with a 3.7 hours per day utilization rate.
Finally, dividing the number of subscribers by the ratio of customers per battery swap spot yields the total number of spots required.

The cost of each range extension position is computed based on the battery charging equipment, which varies with vehicle battery size, plus a flat fee to cover other costs. Charger power is calculated via Equation 1 (see below) to ensure batteries are recharged to $80 \%$ of their available energy in a 30 -minute period. The number of chargers installed per position is calculated to ensure a maximum time between consecutive vehicles of 3 , 5, or 7 minutes, targeting approximately 30 minutes per battery charge while accounting for the 1-minute swap time. This corresponds to 11,7 , and 5 chargers per swap spot, respectively, with rated charger powers ranging from $44 \mathrm{~kW}$ to $101 \mathrm{~kW}$ depending on the time between swaps and vehicle configuration. Total charging equipment cost per swap spot is determined by multiplying the power of each individual charger, the number of chargers per swap spot, and a $\$ 200 / \mathrm{kW}$ cost coefficient taken from recent announcements of fast charger technology [21].

Charge Power $(\mathrm{kW})=1.5$ * Battery Available Energy $(\mathrm{kWh})$ / $0.5 \mathrm{hr}$

Equation 1

Note that in addition to its effect on infrastructure cost, the maximum time between swaps could significantly affect subscriber satisfaction during high traffic times. Arriving at a swap spot with a line of waiting customers and a maximum time between swaps of 7 minutes could result in a wait of more than 20 minutes, frustrating current subscribers and discouraging the enrollment of future ones. Thus service providers will need to carefully balance the cost benefits of increasing maximum time between swaps with its potentially negative impact on the subscriber experience.

The flat fee is varied from $\$ 100,000$ to $\$ 400,000$, and assumes to cover the cost of land, the building, the battery swapping mechanism, thermal management systems, computers, installation, commissioning, and other related elements. Combined with the variable cost of charging equipment described above, this results in total swap-spot costs that vary from a low of $\$ 143,928$ for the BEV50 charged to $100 \%$ maximum SOC with a $\$ 100,000$ flat fee and 7 minutes maximum between swaps, to a high of $\$ 622,786$ for the BEV100 charged to $90 \%$ maximum SOC with a $\$ 400,000$ flat fee and 3 minutes maximum between swaps. The total annual service provider expenditure on battery swap spots then becomes the incremental number of positions required in a given year multiplied by the individual position cost.

\subsubsection{Battery Expenditures}

The number of batteries purchased in a given year is equal to the number of new customers, plus the number of additional 
batteries required by new battery swap-spot infrastructure, plus the number of batteries required to replace those removed from service due to wear. The number of batteries purchased for each new swap spot is equivalent to the number of chargers installed at said swap spot. The number of replacement batteries is calculated based on the average battery lifetime per Table 2 and the history of new customer and swap-spot battery purchases.

The manufacturing cost of each battery is computed using the size of the battery for the specific range and maximum SOC combination as reported in Table 1 and one of the three aforementioned battery costs. A manufacturing-to-retail markup factor of $1.5[\underline{5}, \underline{6}, \underline{7}]$ and a sales tax rate of $6.2 \%$ are included to calculate the cost of each battery to the service provider. We then compute the total annual battery expenditure from the number of batteries purchased and the cost of each battery.

We include the option of crediting the battery's salvage value at the end of its automotive life assuming it sees service in a second-use application. Second-use salvage value is computed per noted methods [22, 23] , assuming $\$ 18 / \mathrm{kWh}$ for repurposing, a 0.75 used product discount factor, and health factor of 0.67 . The value of 0.67 is based on our calculations of second-use battery life for the $80 \%$ range at EOL requirement per documented methods and assumed duty cycles [23]. When second use is dismissed, we set the battery salvage value to zero, effectively assuming that the cost or value of EOL handling (i.e., disposal or recycling) is negligible.

\subsubsection{Operating Expenses}

The main operating expense for the service provider is electricity. The price of commercial electricity per $\mathrm{kWh}$ shown in Figure 5 is taken from the Annual Energy Outlook 2011 with Projections to 2035 [10] and multiplied by the amount of consumed electricity per subscriber (Table 2) and the amount of subscribers per year to yield the total cost of electricity to the service provider. Annual electricity numbers include an assumed efficiency of $85 \%$ for at-home charge points, and $75 \%$ for the batteries charged on the higher-rate swap-spot charging equipment. A fee of $\$ 20 / \mathrm{kW} /$ month is applied to the peak battery charging load at each range extension position to represent demand charges similar to those of Southern California Edison's TOU-GS-3-SOP [24] and San Diego Gas \& Electric's AL-TOU [25] rate schedules. Total demand charges vary from $\$ 797$ to $\$ 19,800$ per month per position.

We also include annual operating costs of $\$ 25,000$ for each battery swapping position to cover maintenance of onsite equipment, a fraction of an attendant's salary (noting that multiple swap spots are likely to be installed at the same location), and other miscellaneous recurring costs. Finally, we include the cost of general and administrative activities at the cost of $\$ 100$ per subscriber per year.

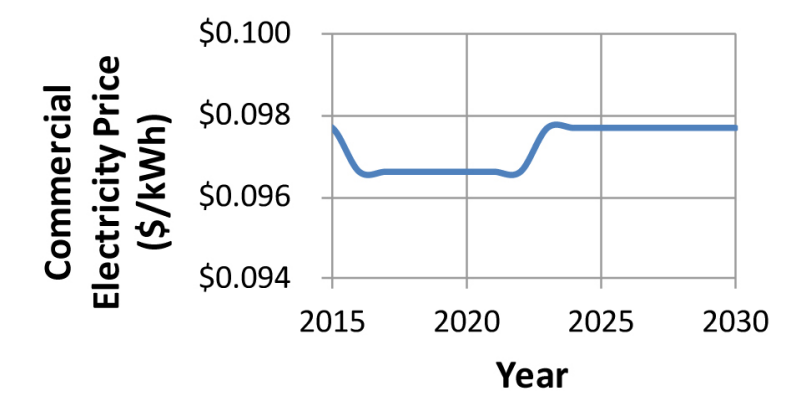

Figure 5. Employed commercial electricity prices (2012 dollars)

\subsubsection{Service Provider Fee Results: Sensitivity to Variables}

We calculate the monthly service provider fee for an expansive set of ROE, cost of debt, maximum SOC, vehicle range, battery manufacturing cost, fast-charge wear factors, second-use health factors, battery swap-spot utilization rate, maximum time between swaps, and swap-spot flat fee values as detailed in the previous sections. All told, this results in thousands of unique combinations of these variables.

To assess the impact of an individual variable, we perform a sensitivity analysis of the monthly service fee for each variable. For each variable, we calculate the median service fee of all cases where the variable of interest is at best-case (encouraging lower service provider fees) and worst-case (encouraging higher service provider fees) values, then rank the importance of that variable based on the difference in the two calculated median service fees (see Figure 6).

For example, to study the effect of battery cost on the service provider fee, we first calculate the median of all service fees where the battery cost is set to $\$ 125 / \mathrm{kWh}$ (yielding a median service fee of $\$ 257 /$ month). We repeat this process when battery cost is set to $\$ 475 / \mathrm{kWh}$ (yielding a median service fee of $\$ 472 /$ month). The large difference in median service fees (\$215/month) indicates the high level of impact that battery cost has on service fee; indeed, in Figure 6 we see that battery cost is the most sensitive variable in this analysis.

It is clear that across the range of variables considered in this analysis, the cost of batteries, cost of financing, and the battery swap-spot utilization rate are the most predominant factors driving the service fee value. At the opposite end of the spectrum, we find that the maximum SOC, swap-spot flat fee, and the fast-charge wear factor have negligible impact on the service fee. 


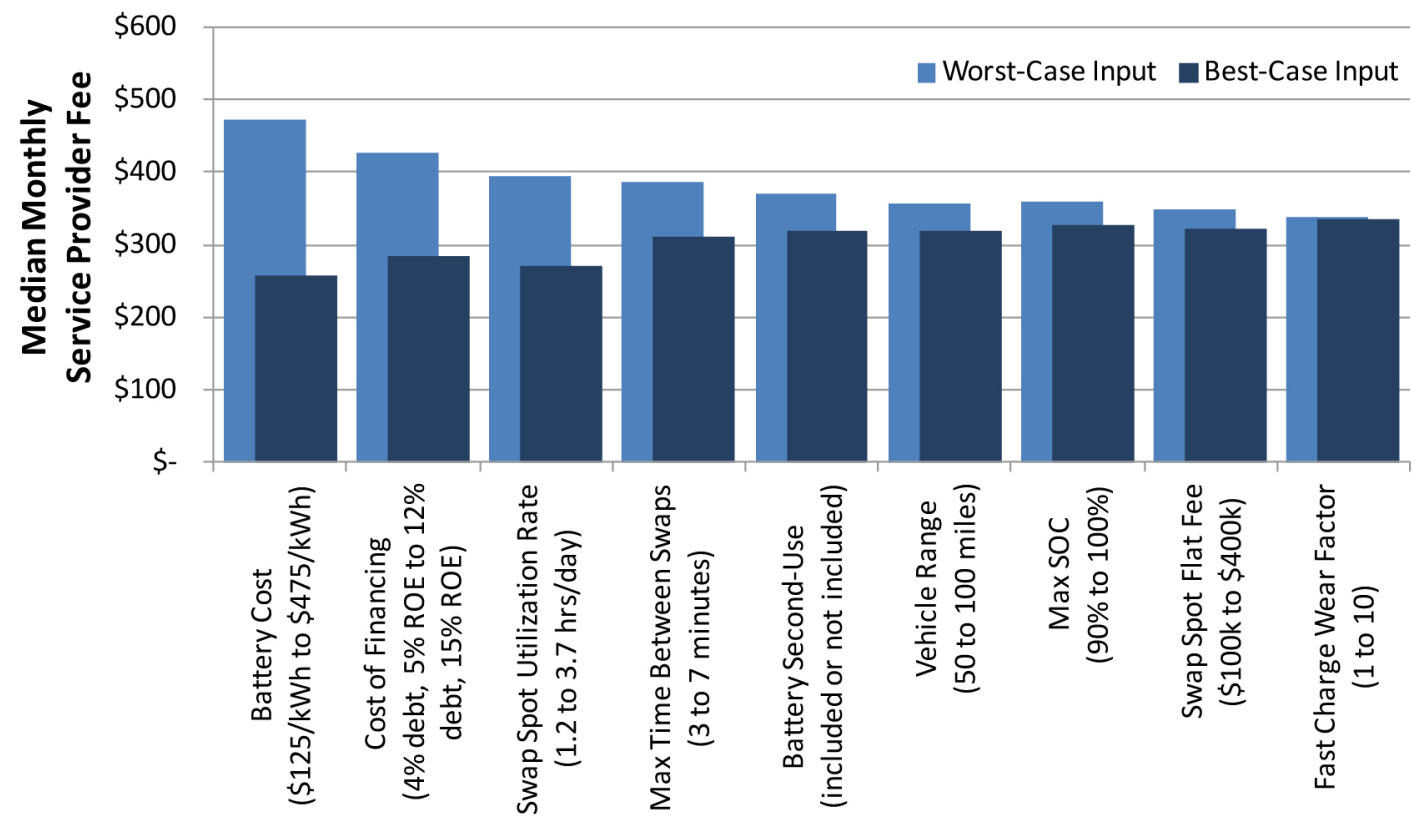

Figure 6. Sensitivity of battery swapping service plan fee to variables

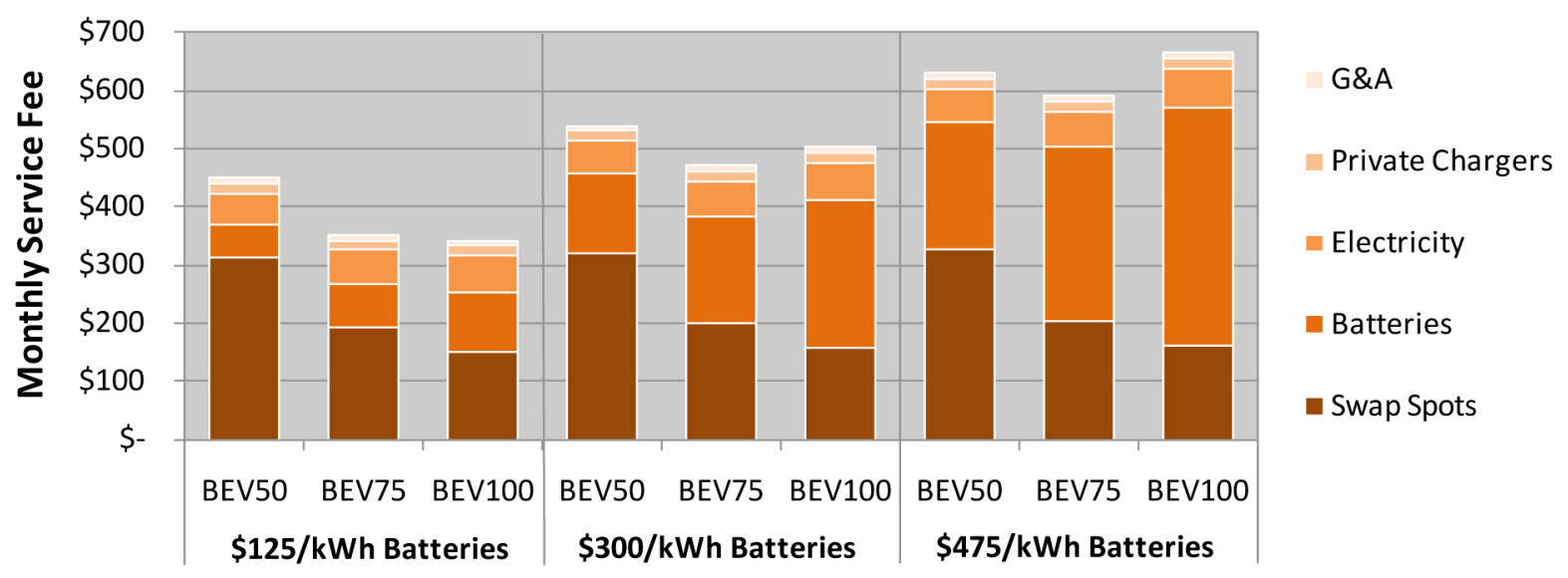

Figure 7. Battery swapping service fee breakdown for the high-service, high-cost range extension class

\subsubsection{Service Provider Fee Results: Cost Breakdown}

Before digging deeper into the service provider cost results, we limit our investigation to a subset of variables. First, we eliminate from consideration multiple maximum SOCs and fast-charge wear factors due to their small impact, proceeding only with a $90 \%$ maximum SOC and the $10 \mathrm{x}$ wear factor to compose a conservative fast charging scenario. Second, we eliminate consideration of battery second use, as it also has a small impact and comes with considerable uncertainty. Third, we group the swap-spot infrastructure variables into two classes:

(1). A high-service, high-cost class where the utilization rate and the maximum time between swaps are set to the minimum values, and the swap-spot flat fee is set to the maximum value.
(2). A low-service, low-cost class where the swap-spot utilization rate and the maximum time between swaps are set to the maximum values, and the swap-spot flat fee is set to the minimum value.

Finally, we restrict the cost of financing to the medium case ( $8 \%$ cost of debt and $10 \%$ return on equity) on the basis that the low values are unlikely without government participation, and the high values are unlikely to support a compelling business case relevant to mass markets due to the resultant high SP fees.

The cost of batteries, vehicle range, and the range extension class become our remaining variables of study. The breakdown of the monthly service fee for these remaining cases is shown in Figures 7 and $\underline{8}$. 


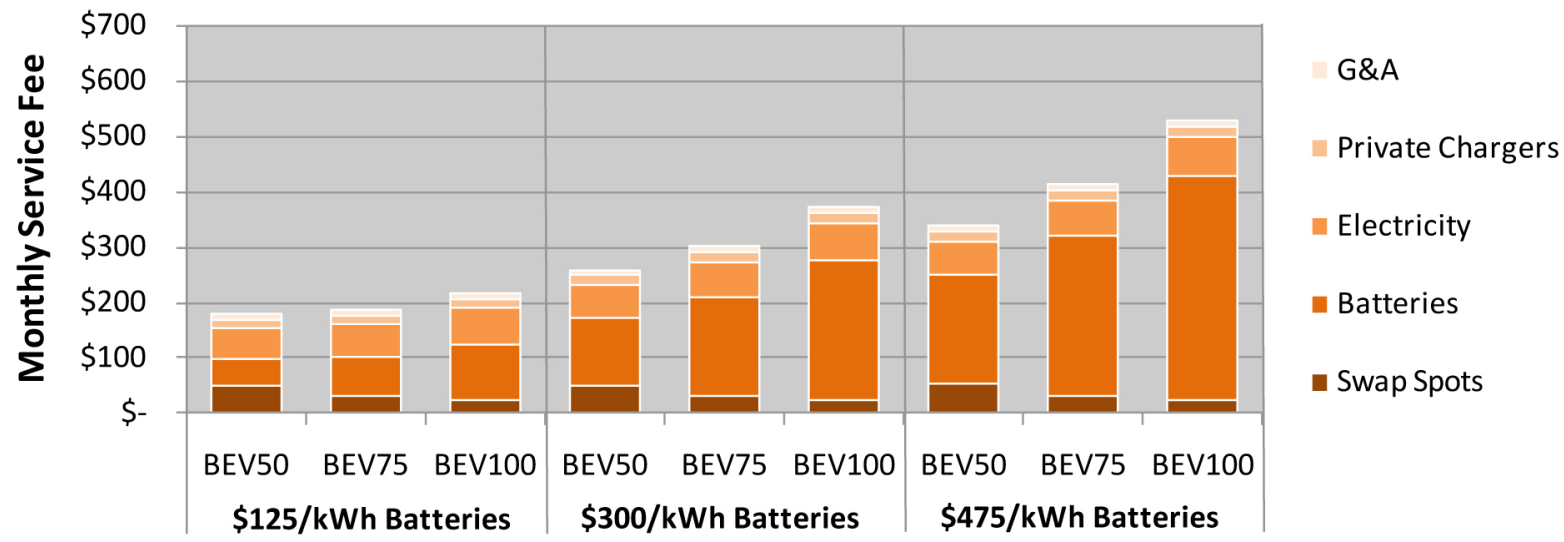

Figure 8. Battery swapping service fee breakdown for the low-service, low-cost swap-spot class

The most clearly evident point that arises from these results is that there is a strong difference in service fees between the two range extension classes. Clearly, the quantity and cost of infrastructure deployed-and thereby the level of service to the subscriber-is an important driver of service fee. With the high-cost, high-service class we see that the cost of swap spots is always a significant component of the total cost breakdown, and often the largest single cost element. This incentivizes a careful trade-off of vehicle range and infrastructure deployment to minimize total cost. Our results suggest that the optimum vehicle range is between 50 and 100 miles when battery prices are at or above $\$ 300 / \mathrm{kWh}$.

Alternatively, the low-cost, low-service swap-spot class encourages less vehicle range to minimize cost. However, it must be noted that at such short vehicle ranges, subscribers will visit swap spots much more frequently, and the effect of the level of service on subscriber satisfaction will be compounded.

\subsection{Individual Driver Economics}

In this section we investigate the individual driver economics of likely subscribers (identified in Section 4.1) using realistic assumptions on swap-spot utilization (Section 4.2) and bottom-up calculated service fees (Section 4.3). Relative to the individual driver simulations performed in Section 4.2 to compute SP usage statistics, the only parameter changes are the SP fee and the ratio of total batteries in circulation to the number of customer vehicles. As we compute no financial metrics in Section 4.2, the change in the SP fee has no impact requiring further consideration; however, the change in the battery ratio affects battery lifetime, which could affect the other usage statistics, and in turn necessitate revisiting our SP fee calculations. Accordingly, before discussing individual driver economics, we take a moment to compare the usage statistics calculated in Section 4.2 with the observed usage statistics calculated with updated in-vehicle to at-swap-spot battery ratios.
Previously, we assumed that 7 batteries were being charged or resting at a swap spot for every 100 vehicles on the road. However, here we have applied values calculated in Section 4.3, ranging from 0.7 (SP-BEV100; low-cost, low-service swap-spot class) to 18.0 (SP-BEV50; high-cost, high-service swap-spot class) batteries being charged or resting at a swap spot for every 100 vehicles on the road. The implication of reducing the number of extra batteries in rotation is to increase the number of cycles for each battery, and vice versa. We find that this change increases the average battery life of the BEV50 from 11.6 years to 14.3 years, due to the significantly reduced cycling per battery that results from updating our original assumption. The increase in cycling applied to the BEV100, on the other hand, has a negligible impact on its battery life. The battery life of the BEV75 is largely unaffected as the number of extra batteries only changes slightly from our initial assumption. The remaining usage statistics - electricity use, utility factor, and annual battery swap frequency - are not noticeably affected. As the only impact of the adjusted battery ratio is a $30 \%$ increase in SP-BEV50 battery life, the financial impact of which will be marginalized by the time-value of money and the service provider's ability to depreciate battery wear, we continue our analysis without an update to our calculated SP fees.

Moving now to driver economics, we present the results of our final TCO calculations in Figure 9. Subplot (a) of this figure shows the frequency at which electing the SP-BEV is more cost-effective than electing a DO-BEV75. It includes all three vehicle ranges and battery prices and both the low-cost, low-service and high-cost, high-service range extension classes, illustrating that the SP-BEV can be more economical than a DO-BEV for many of the down-selected high-mileage drive patterns with a broad spectrum of conditions. This is due primarily to the fact that available battery swapping increases the utility of the BEV and greatly reduces these drivers' unachievable VMT, which can be a major cost when a driver must rent a separate vehicle to complete this travel. However, the subplot (b) shows that electing a SP-BEV is only more cost-effective than both the DO-BEV75 and DO- 


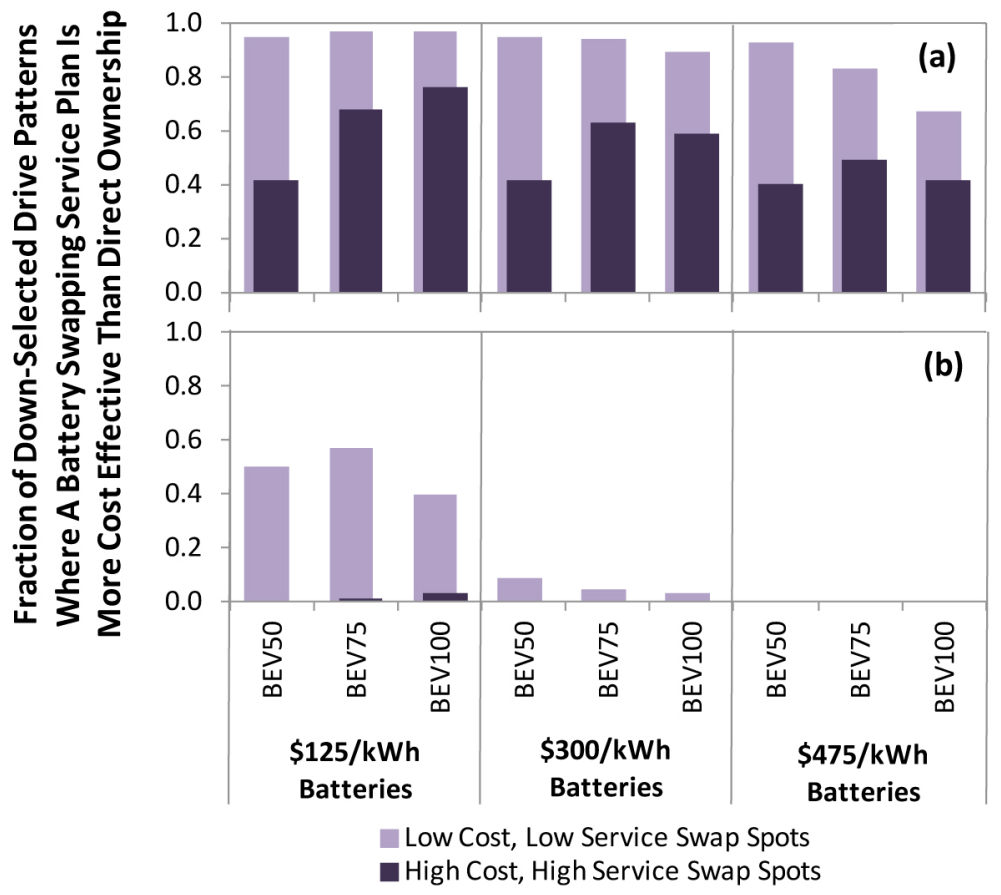

Figure 9. Frequency at which a SP-BEV is (a) more cost-effective than a DO-BEV75, and (b) more cost-effective than both a DO-BEV75 and a DO-CV

$\mathrm{CV}$ in significant numbers when both the cost of batteries and swap-spot infrastructure is low.

\section{CONCLUSIONS}

In this study we have analyzed the economics of BEVs operated with a service plan where battery swapping is available to extend vehicle range. Our evaluation process followed four steps: (1) identifying drive patterns best suited to a battery swapping service plan, (2) modeling service usage statistics for the selected drive patterns, (3) calculating the cost of service plan options given these statistics, and (4) evaluating the economics of individual drivers with realistically priced service plans. For comparison, we have also calculated the TCO of both a BEV75 and a CV operated with a conventional DO scenario. A high-fidelity battery degradation model has been employed throughout to forecast battery wear, its effect on vehicle range, and required battery replacements. Real-world drive patterns from the TCS project have been utilized to support the calculation of realistic battery usage, the frequency of battery swapping events, and the fraction of achievable VMT. The cost of unachievable VMT has been accounted for based on the cost of popular car-share programs, making our results most generally applicable to drivers without access to an alternative lowercost, range-unlimited mode of transportation (e.g., a second non-BEV car owned by or freely available to said driver). Further, a detailed accounting of the economics of a battery swapping service provider, including consideration of the amount of required infrastructure, financing of capital expenditures, taxes, depreciation, etc., has been applied to calculate the fee charged to the consumer for battery swapping service plans.

As should be expected, we find that drive patterns with high annual VMT are generally best suited to range extension (e.g., battery swapping) SPs. The range extension infrastructure utilization to be expected from such drive patterns varies considerably-primarily as a function of the range of the $\mathrm{BEV}$, where shorter $\mathrm{BEV}$ ranges encourage a higher frequency of range extension events. For all vehicle ranges, though, the achievable utility factor is high when range extension infrastructure is adequately placed and up to four range extensions per day are allowed, spanning from a low of $85 \%$ at 50 miles to a high of $94 \%$ at 100 miles.

In calculating the monthly service fee of a battery swapping SP, we find that the high level of capital expenditures involved in the service provider's business model makes the cost of financing very powerful. The large capital costs are generally best attributed to the cost of batteries (as opposed to infrastructure, electricity, charge points, and other general and administrative costs). However, if the cost of individual battery swap-spots approaches or exceeds the high end of our assumptions, and geographic and/or customer service requirements demand a high number of swap-spot deployments per customer, infrastructure costs can compete with and even exceed those of batteries.

In applying the calculated service fee to individual driver economics where the cost of unachievable VMT is high, our simulations show that the economic efficiency of a battery 
swapping SP-BEV is often challenged by the cost of batteries, infrastructure, and financing. With our assumed cost of gasoline, tax structure, and absence of purchase incentives, we find that these factors generally make the TCO of the SP-BEV more expensive than that of a DO-CV. Only when battery costs reach the DOE's most aggressive target $(\$ 125 / \mathrm{kWh})$, and infrastructure costs achieve our lowest assumed values, do we see significant numbers of drive patterns benefiting economically over the CV option.

However, where the cost of unachievable VMT is high, we do find the SP-BEV to be a more cost-effective approach to electrifying travel for a significant number of drive patterns than a DO-BEV75 with a broad range of scenarios for the cost of batteries and infrastructure. There is also additional potential for service providers to improve the relative value of BEVs via multi-tiered fee and service strategies, optimal allocation and down-cycling of aged batteries, and revenue generation via vehicle-to-grid services (which a service provider is well positioned to optimize).This, along with several assumptions and simplifications made in this analysis, encourage further study of battery swapping service plans. Along with these aforementioned avenues for value improvement, such efforts must also address several aspects of battery swapping SP business models that could detract value, including accounting for business start-up costs (which could be significant in the years before the venture generates any revenue); marketing, engineering, and management staff expenses; increased cost to the vehicle glider for a swappable battery; and increased infrastructure utilization due to the geographic and temporal distribution of subscriber battery swapping needs and other unaccounted for driver behavior (e.g., range anxiety). Further, the concurrence of both a high cost of unachievable VMT and high annual VMT, which may decrease the potential customer base, should be considered. Finally, other elements that are more difficult to quantify economically must be addressed as well - such as customer willingness to subscribe to a service contract for battery service while owning a vehicle without a battery, to increase stopping frequency on long travel days.

\section{REFERENCES}

1. Neubauer, J.; Wood, E.; Brooker, A. "Sensitivity of battery electric vehicle economics to drive patterns, vehicle range, and charge strategies," Journal of Power Sources, July 1, 2012, Vol. 209, pp. 269-277.

2. Neubauer, J.; Wood, E.; Brooker, A. "Sensitivity of plugin hybrid electric vehicle economics to drive patterns, electric range, energy management, and charge strategies," Journal of Power Sources, available online July 27, 2012.

3. Traffic Choices Study - Summary Report, Puget Sound Regional Council, April 2008.

4. Electrical and Electronics Technical Team Roadmap, Dec. 2010. Accessed June 5, 2012: http://www1.eere.energy.gov/ vehiclesandfuels/pdfs/program/eett roadmap 12-7-10.pdf, [].
5. Rogozhin, A.; Galaher, M.; Helfand, G.; McManus, W. "Using indirect cost multipliers to estimate the total cost of adding new technology in the automobile industry," Int. J. Production Economics, April 2010, Vol. 124, Issue 2, pp. 360-368.

6. Vyas, A.; Santini, D.; Cuenca, R. "Comparison of indirect cost multipliers for manufacturing." Argonne, IL: Argonne National Laboratory, Center for Transportation Research, Energy Systems Division, April 2000.

7. "Study of industry-average mark-up factors used to estimate changes in retail price equivalent (RPE) for automotive fuel economy and emissions control systems," Sierra Research, Inc., Sacramento, CA. November 21, 2007.

8. "Revisions and Additions to Motor Vehicle Fuel Economy Label; Final Rule," Federal Register, Vol. 76, No. 129, Wednesday, July 6, 2011, Rules and Regulations. Accessed Sept. 22, 2011: http://www.gpo.gov/fdsys/pkg/ FR-2011-07-06/html/2011-14291.htm.

9. Lohse-Busch, H. "Small EV Testing and Analysis," Presentation to DOE. Argonne National Laboratory, November 17, 2009.

10. "Annual Energy Outlook 2011 with Projections to 2035," U.S. Energy Information Administration, DOE/ EIA-0383(2011), April 2011.

11. "Weekly U.S. Regular All Formulations Retail Gasoline Prices," U.S. Energy Information Administration. Accessed June 5, 2012: http://www.eia.gov/dnav/pet/hist/

LeafHandler.ashx? $\mathrm{n}=$ PET\& $\mathrm{s}=\mathrm{EMM}$ EPMR_PTE_NUS_DPG\& $\mathrm{f}=\mathrm{W}$.

12. Howell, David, "Annual Merit Review: Energy Storage R\&D and ARRA Overview," Vehicle Technologies Program, March 2011, U.S. Department of Energy, Energy Efficiency and Renewable Energy. Accessed June 5, 2012: http:// www1.eere.energy.gov/vehiclesandfuels/pdfs/ merit_review_2010/electrochemical_storage/ es00a howell 2010 o.pdf.

13. Dinger, A.; Martin, R.; Mosquet, X.; Rabi, M.; Rizoulis, D.; Russo, M.; Sticher, G. "Batteries for Electric Cars: Challenges, Opportunities, and the Outlook to 2020;" Boston Consulting Group: 2010. http://www.bcg.com/documents/ file36615.pdf

14. Smith, K., Earleywine, M., Wood, E., Neubauer, J. et al., "Comparison of Plug-In Hybrid Electric Vehicle Battery Life Across Geographies and Drive Cycles," SAE Technical Paper 2012-01-0666, 2012, doi:10.4271/2012-01-0666.

15. Simpson, M.; Markel, T. "Plug-in Electric Vehicle Fast Charge Station Operational Analysis with Integrated Renewables," EVS26 (Electric Vehicle Symposium) 2012.

17. "National and State Corporate Income Tax Rates, U.S. States and OECD Countries, 2011," Tax Foundation. Accessed: June 5, 2012: http://taxfoundation.org/article/ 
national-and-state-corporate-income-tax-rates-us-states-andoecd-countries-2011.

18. "Annual Vehicle Distance Traveled in Miles and Related Data - 2008 - By Highway Category and Vehicle Type," U.S. Department of Transportation. Accessed June 5, 2012: http:// www.fhwa.dot.gov/policyinformation/statistics/2008/ vm1.cfm.

19. "The EPA 10 Gallon Per Minute Fuel Dispensing Limit," U.S. Environmental Protection Agency. Accessed June 5, 2012: http:/www.epa.gov/oms/regs/ld-hwy/evap/spitback.txt.

20. Alternative Fuels Data Center. Accessed June 5, 2012: http://www.afdc.energy.gov/afdc/data/ infrastructure.html\#transport.

21. "Nissan Leaf, Mitsubishi i Rapid Charging Gets Cheaper Thanks To Nissan," Green Car Reports. Accessed June 5, 2012: http://www.greencarreports.com/news/ 1068509 nissan-leaf-mitsubishi-i-rapid-charging-getscheaper-thanks-to-nissan.

22. Neubauer, J.; Pesaran, A. "The ability of battery second use strategies to impact plug-in electric vehicle prices and serve utility energy storage applications." Journal of Power Sources, 2011, Vol. 196, Issue 23, pp. 10351-10358.

23. Neubauer, J., Pesaran, A., Williams, B., Ferry, M. et al., "A Techno-Economic Analysis of PEV Battery Second Use: Repurposed-Battery Selling Price and Commercial and Industrial End-User Value," SAE Technical Paper 2012-01-0349, 2012, doi:10.4271/2012-01-0349.

24. "Schedule TOU-GS-3-SOP Time-of-Use - General Service - Super Off-Peak - Demand Metered." Southern California Edison. Accessed: June 5, 2012: http:// www.sce.com/NR/sc3/tm2/pdf/ce282.pdf.

25. "Customer Rate Information Schedule AL-TOU Secondary," San Diego Gas \& Electric. Accessed June 5, 2012: http://www2.sdge.com/tariff/com-elec/ ALTOUSecondary.pdf.

26. "Convenience and Petroleum Retailing Totals, Trends and Analysis of 2007 Industry Data.” NACS (2008), Alexandria, VA.

27. "Better Place Extends Tokyo Battery Swap Trial for Additional Three Months," Green Car Congress. Accessed June 5, 2012: http://www.greencarcongress.com/2010/08/ better-place-extends-tokyo-battery-swap-trial-for-additionalthree-months.html.

28. Hensley, R.; Knupfer, S.; Pinner, D. "Electrifying cars: How three industries will evolve," McKinsey \& Company: 2009.

29. Lache, R.; Galves, D.; Nolan, P. "Vehicle Electrification: More rapid growth; steeper price declines for batteries," Deutsche Bank: 2010.

\section{ACKNOWLEDGEMENT}

This study was supported by the Energy Storage, Vehicle Technologies Program, Office of Energy Efficiency and
Renewable Energy, U.S. Department of Energy. The authors would specifically like to thank Dave Howell and Brian Cunningham of the U.S. Department of Energy for their continued guidance and support. The use of the battery degradation and FASTSim vehicle simulation tools, both developed at the National Renewable Energy Laboratory with funding from the U.S. Department of Energy's Vehicle Technologies Program, were critical to the completion of this study. Special thanks to Aaron Brooker for development of FASTSim and support of the Battery Ownership Model; Kandler Smith for developing and supporting the integration of the battery degradation model; and Terry Penney and Ahmad Pesaran, for their continual guidance.

\section{DEFINITIONS/ABBREVIATIONS}

BEV - Battery electric vehicle

BOL - Beginning of life

BOM - Battery Ownership Model

CV - Conventional vehicle

DO - Direct ownership

DOE - Department of Energy

DVMT - Daily vehicle miles traveled

EIA - Energy Information Administration

EOL - End of life

PDF - Probability density function

ROE - Return on equity

SOC - State of charge

SP - Service plan

TCO - Total cost of ownership

TCS - Traffic Choices Study

VMT - Vehicle miles traveled 
The Engineering Meetings Board has approved this paper for publication. It has successfully completed SAE's peer review process under the supervision of the session organizer. This process requires a minimum of three (3) reviews by industry experts. ISSN 0148-7191
Positions and opinions advanced in this paper are those of the author(s) and not necessarily those of SAE. The author is solely responsible for the content of the paper.

SAE Customer Service:

Tel: 877-606-7323 (inside USA and Canada)

Tel: 724-776-4970 (outside USA)

Fax: 724-776-0790

Email: CustomerService@sae.org

SAE Web Address: http://www.sae.org

Printed in USA 